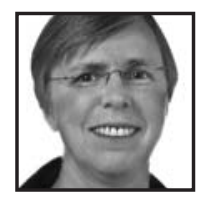

\title{
Relatedness-Supportive Learning Environment for Girls in Physical Education
}

\author{
Sandra L. Gibbons, University of Victoria
}

\begin{abstract}
The challenges and issues associated with girls' disengagement from high school physical education are serious and long standing. This disengagement has provided the impetus for the examination of alternative strategies to facilitate girls' engagement in physical education. The purpose of this paper is to share a range of gender-inclusive practices in physical education grounded in the concept of a relatedness-supportive learning environment. "Relatedness" is the feeling of being connected to others in a social context. In turn, "relatedness support" refers to the social environments in which individuals have the opportunity to develop healthy relationships with others.
\end{abstract}

\section{Introduction}

esearch in physical education (PE) classrooms suggests that students'
social interactions and involvement are pedagogical goals that enhance
learning. These goals suggest a connection between the teacher's ability to create a learning environment that emphasizes students' social interactions and the enhancement of students' individual and social growth. This paper considers adolescent girls' need for a sense of relatedness in physical education and shares a range of gender-inclusive practices grounded in the concept of a relatedness-supportive learning environment. Relatedness is a concept drawn from self-determination theory of motivation. 
This paper represents a synergy of two of my ongoing areas of research. The first area has focused on descriptive research to better understand the experiences of girls and young women in physical education (e.g., Gibbons, Wharf Higgins, Gaul, \& Van Gyn, 1999; Gibbons \& Humbert, 2008), and program-effectiveness research involving the development and implementation of alternative PE programs designed to meet the needs of female students (e.g., Gibbons \& Gaul, 2004; Gibbons, 2009). Most recently we utilized Deci's and Ryan's $(1985,2000)$ self-determination theory [SDT] of motivation as the theoretical framework to analyze and adapt curriculum and teaching practices in PE to increase support the participation of female students (Gibbons, Humbert, \& Temple, 2010). The second research area has explored the systematic implementation of team-building activities in physical education and their impact on a range of affective outcomes including self-concept, perceptions of competence, and social regard (e.g., Ebbeck \& Gibbons, 1998; Gibbons, Ebbeck, Conception, \& Li, 2010; Gibbons \& Ebbeck, 2011). A notable result of these interventions has been significant positive impact on female participants in particular. This paper merges these two research areas by situating the recurring concept of meeting girls' need for a sense of relatedness in PE as the major focus.

\section{Girls' Involvement in Physical Education}

Girls' disengagement from high school physical education (PE) has been well documented (Azzarito, Solmon, \& Harrison, 2006; Camacho-Minano, LaVoi, \& BarrAnderson, 2011; Flintoff \& Scraton, 2001; Olafson, 2002; van Daalen, 2005). In Canada for example, Gibbons and her colleagues (1999) reported that tenth grade girls described their PE experience as boring and repetitive, and they planned to leave PE as soon as the option became available. This disengagement has provided the impetus for the examination of alternative curricula to facilitate girls' engagement in $\mathrm{PE}$, and the exploration of the type of learning environment preferred by girls. From the alternative curriculum perspective, several studies (Felton et al., 2005; Jamner, Spruit-Metz, Bassin, \& Cooper, 2004; Lubans et al., 2012; Webber et al., 2008) reported positive results from PE interventions designed specifically to accommodate the learning needs of adolescent girls. For example, Felton et al. (2005) reported positive changes in girls' physical activity levels in their investigation of the Lifestyle Education for Activity Program (LEAP). They coined the term "girl-friendly PE" to refer to seven features of the PE component of LEAP: (a) gender separation opportunities in class, (b) noncompetitive activities are offered, (c) lifelong physical activity is emphasized, (d) students are physically active in class, (e) classes are fun and enjoyable, (f) behavioral skills for PE are taught, and (g) appropriate instructional methods (including smalls groups) are used (Felton et al., 2005). In Canada, several studies (Gibbons, 2009; Gibbons \& Gaul, 2004) 
found that girls would enroll and willingly participate in senior elective PE courses if the courses incorporated similar features to those highlighted in girl-friendly PE. For example, Gibbons and Gaul (2004) found that the girls placed considerable significance on the opportunity to have an active role in the planning process, choice of physical activities, and a socially supportive learning environment.

This research on alternative physical education curricula to meet the needs of girls is situated within the broader discussion of innovative models for curriculum and pedagogy. A range of contemporary models (e.g., sport education, personal and social responsibility, cooperative learning) have been developed in order to better address the increasingly diverse needs of students and those goals in physical education that extend beyond the learning of movement skills (Dowler, 2012; Dyson \& Casey, 2012; Gordon, 2010; Grenier \& Yeaton, 2012; Hellison \& Martinek, 2006; Pascual et al., 2011; Ullrich-French, McDonough, \& Smith, 2012). The relatedness-supportive learning environment in this paper takes a similar focus on personal and social development.

From the learning environment perspective, researchers (e.g., Gano-Overway, 2013; Hills, 2007; Hurtes, 2002; Leversen, Danielsen, Wold, \& Samdal, 2012) have highlighted the centrality of relational development to girls' learning in physical education and identified some notable gender differences. In their examination of social interaction preferences for learning in PE among secondary students, Ruiz, Graupera, Moreno, and Rico (2010) found that girls preferred a learning environment that emphasized cooperation and affiliation, compared to the boys' preference for competition and individual achievement. For girls, to win or lose was not their principal motivation for learning in PE classes. Girls preferred more social interactions and to help others to participate in tasks (Ruiz et al., 2010). The researchers concluded that boys and girls preferred to learn within these different social structures and they preferred different kinds of interactions. According to Hills (2006, 2007), girls give more emphasis than boys to social relationships in PE and try to include everyone. Similarly, Leversen et al. (2012) reported that regardless of the physical activity, girls were more conscious of their social needs than their male counterparts.

\section{Relatedness Research in Physical Education}

Self-determination theory describes how motivation develops and its influence on behaviour. First, there are three innate psychological needs-autonomy, competence, and relatedness - that determine the state of motivation an individual will display (Deci \& Ryan, 1985, 2000; Ryan \& Deci, 2002, 2007). If an individual's need for autonomy (having a sense of choice), competence (a sense of efficacy), and relatedness (sense of 
social attachment) are met, they will be intrinsically motivated to engage in certain behaviour. In turn, an individual's state of motivation influences behaviour, affect, and cognition. Researchers have found the self-determination theory (SDT) of motivation to be particularly helpful in understanding overall student involvement in PE (Bryan \& Solmon, 2007; Sun \& Chen, 2010; van den Berghe, Vansteenkiste, Cardon, Kirk, \& Haerens, 2012).

Collectively, research on the three innate psychological needs has demonstrated the importance of students' perceptions of a mastery climate, autonomy support, and choice to their feelings of competence and autonomy in physical education (Rutten, Boen, \& Seghers, 2012; Shen, McCaughtry, Martin, \& Fahlman, 2009; Standage, Duda, \& Ntoumanis, 2003, 2005, 2006; Sun \& Shen, 2010; van den Berghe et al., 2012). Compared to the concepts of autonomy and competence, there has been far less research emphasis on the factors most likely to help students feel socially related during their physical education classes. "Relatedness" is defined as the feeling of being in relation to others in a social context (Ryan \& Deci, 2002). "Relatedness support" refers to the social environments in which individuals have the opportunity to develop inspiring relationships with others (Cox, Duncheon, \& McDavid, 2009; Ullrich-French et al., 2012). Despite this lack of research attention, Cox and Williams (2008) suggest that the identification of factors that may support students' feelings of relatedness is particularly important, as studies have demonstrated that feeling socially connected can be a stronger predictor of self-determined motivation than feelings of competence or autonomy in physical education.

Several researchers (Eime et al., 2013; Ntoumanis, 2001, 2005; Pfaeffli \& Gibbons, 2010; Sammet, 2010; Shen, McCaughtry, Martin, Fahlman, \& Garn, 2102) have highlighted the need for relatedness as particularly important for girls, and that social relationships play an important role in their participation (Hills, 2007). Shen et al. (2012) suggest that "a sense of relatedness is one of the key self-system processes that individuals develop over time in response to interactions with the social context" (p. 214). In their examination of the experiences of adolescent girls in PE, Shen and his colleagues found that girls with a high sense of relatedness were more likely to show enthusiastic participation and effort in PE class. As well, they noted that female students' feeings of relatedness to their teachers was found to be a significant predictor of their level of engagement in PE class. Specifically, those girls who felt "important and appreciated by their teachers were more likely to report that their involvement in physical activities were interesting and fun and they felt happy and comfortable in physical education" (p. 241). The importance of supportive relationships with peers in PE class was also found to modify the effects of relatedness to teachers. In particular, girls with low feelings of 
relatedness to their teachers were signficantly more involved in PE if they felt accepted by their peers.

In their examination of a senior PE course tailored to meet the needs and interests of adolescent girls, Pfaeffli and Gibbons (2010) found that the girls emphasized the sense of connection they felt in an all-girls' course, expressing the importance of participating with friends, making new friends, and feeling safe. These authors suggest that for many girls, their relatedness is clearly tied to their willingness to positively engage in PE class. They further propose that without the sense relatedness and support, it appears unlikely that girls will sufficiently let their guard down to get involved in PE.

In their comprehensive review, Weiss and Stuntz (2004) emphasized the potential for the physical education context as a medium for improving peer relationships. They suggested that examining instructional activities that focus on communication, collaboration, and problem solving offer promise in enhancing peer relationships through emphasis on group trust and social support. As well, recent research (e.g., Niemiec \& Ryan, 2009; Sproule et al., 2013; Ullrich-French, McDonough, \& Smith, 2012) emphasizes the need to explore the instructional processes that contribute to social connectedness. With this in mind, the following section presents a wide array of actions for teachers that may enhance a relatedness-supportive environment in PE that will contribute directly to girls' positive involvement.

\section{Relatedness-Supportive Learning Environment: Suggestions for Action}

Whereas many researchers emphasize female students' need for a sense of relatedness in their physical education class, few have provided practical suggestions for teachers beyond brief generalities. For example, Niemiec and Ryan (2009) stated their suggestions for applying relatedness-supportive strategies in the classroom in one short sentence: "strategies for enhancing relatedness include conveying warmth, caring, and respect for students" (p. 141). Similarly, in their discussion of implications for practice, Shen et al. (2012) advise teachers to exhibit the qualities of "warmth, caring, sensitivity, dedication of attention and time, and emotional availability"(p. 243) as suggested strategies to enhance relatedness in their PE classes. The purpose of this section is to provide specific, practical, and theoretically grounded actions for teachers to implement to enhance the potential for creating a relatedness-supportive learning environment in their PE classrooms. The following table is presented in two sections. The first section, "Community building inside the PE classroom," includes actions to help teachers develop supportive and respectful relationships with their students, and actions to help students develop positive relationships with their PE classmates. 
Actions in this first section include curricular content such as team-building and cooperative games, along with a range of organizational strategies, behavioural expectations, and student-centered assessment ideas. In each case, the focus is on helping students interact in a respectful and supportive manner while they are in physical education class. The second section, "Taking PE to the community," includes suggested actions to extend the sense of relatedness beyond the PE classroom, and strengthen the potential for students' long-term engagement in physical activity once their experience in PE ends. Students are encouraged to socially engage in physical activity outside physical education. Actions in this second section include involvement in community physical activity events as either participants or volunteers; service learning; and exploration of community recreation facilities.

\section{Table 1}

\section{Relatedness-Supportive Actions for Teachers}

\section{Community building inside the PE classroom}

\section{Include cooperative games and team-building activities}

- Intersperse team-building and/or cooperative games throughout the term

- Explicitly emphasize the major team-building concepts when using team-building activities (e.g., trust, cooperation, communication, risk)

- Include game-creation activities (e.g., invent-a-game)

\section{Learn about self and others}

- Learn the names of your students as quickly as possible, welcome them into the class

- Help students develop connections with classmates: know names of classmates; icebreakers, etc.

- Use journals for student self-reflection on what they are learning about themselves as a physical activity participant (e.g., what I am proud of, where I want to improve)

- Use a rotating tournament ladder throughout the semester; by the end of the semester everyone has worked with everyone else

\section{Create a respectful and safe environment}

- Set positive tone early in the term (e.g., the BIG messages) — help students feel safe and valued, model the behaviour you expect of your students, reinforce positive behaviour

- Include clear and positive expectations for respectful language (e.g., no swearing, no put-downs)

- Use and encourage inclusive language, address stereotypic language (e.g., girls' pushups)

- Create behavioural rubrics together with students (e.g., ask students how to create a safe environment, what can the teacher do, what can the students do?)

- Implement a respectful process for choosing partners or groups (e.g., must accept first person who asks, if someone doesn't have a group invite them into your group) 


\section{Table 1}

\section{Relatedness-Supportive Actions for Teachers (cont.)}

- Utilize a variety of ways for grouping to help students feel comfortable/safe (e.g., all bright shirts together, start with peer/friend groups first, then mix it up once students are already in activity)

- Explicitly address issues such as bullying, harassment, verbal and physical abuse with specific expectations and consequences

- Include self-defense / personal protection in your PE program

- Regularly recognize students for their positive contributions (e.g., "student of the day")

- At end of semester, hand out sheets with name of all students in class. Students write positive comment about each of her/his classmates. Each student gets his/her sheet with everyone's positive comments.

- Be aware of the expectations of different cultures represented in your PE class with respect to the roles of females and males (including physical activity expectations)

- Ask students what they need to feel comfortable/safe in change room (e.g., written questionnaire)

- Ensure there are privacy options for change rooms (e.g., private change stalls)

- Allow sufficient time to shower and change so students can go to their next class

\section{Include learning outcomes that focus on fair play}

- Have explicit expectations of positive sporting behaviour for game play

- Involve students in establishing acceptable behaviour for game play (e.g., what is acceptable, what is not acceptable; what it means to be a good sport)

- Explicitly highlight positive behaviour to motivate students to act appropriately (e.g., freeze game and highlight the behaviour)

- Use journals for student self-reflection on their own effort and behaviour toward others (e.g., did I try my hardest, did I cheer my classmates)

- Teach the etiquette associated with different activities (e.g., martial arts etiquette, dance etiquette)

- Utilize teaching strategies to increase team play (e.g., number of passes before scoring, points for team work)

- Provide opportunities for students to develop and practice their skills as game officials (e.g., referee, scorekeeping, line judge)

\section{Encourage and assess aspects of social responsibility}

- Include an expectation of daily in-class social responsibility (e.g., help with equipment, be on time, helping others)

- Use a daily BEAP rubric: behaviour, effort, attitude, participation

\section{Provide opportunities for students to learn from each other}

- Use peer tutoring, peer teaching, peer assessment

- Utilize collaborative learning activities (e.g., create a dance, gymnastics routines)

- Use group warm-up / cool-down routine (e.g., circle stretching)

- Use small-sided games (where applicable) to increase student involvement

- Maximize use of equipment to increase practice opportunity (e.g., one ball per pair) 


\section{Table 1}

\section{Relatedness-Supportive Actions for Teachers (cont.)}

- Provide opportunities for students to bring and share their interests/expertise with the group (their own, family members', etc.)

- In co-ed classes/units, use females and males as co-leaders

\section{Use a variety of motivational strategies}

- Include motivational techniques to build and maintain "fun factor/excitement" (e.g., novelty trophies/prizes, pick games from a hat, fun warm-up games)

- Include some physical activities where everyone is at the same level (all beginners) (e.g., Tai Chi may be new to everyone)

- Incorporate novelty activities for change of pace (e.g., rubber chicken games, cup stacking, playground games)

- Utilize the natural environment for physical activity (e.g., parks, trails)

\section{Taking PE to the community (outside the classroom)}

\section{Involve students in volunteer activities (in school and out of school)}

- Involve students in administration of house leagues, intramurals, clubs, etc.

- Participate in community events (e.g., Terry Fox Run, Run for the Cure, Green Earth Day)

- Participate as a volunteer in community events (e.g., work at a water station in a community run)

- Involve students in school-wide events that complement PE (e.g., Wellness Week organized by students)

\section{Include social action projects}

- Have a class project each term. Each class designs something it wants to contribute to the community (focus on physical activity) (e.g., run to the local park and pick up trash, walk with students at local pre-school to the playground and play some games)

\section{Explore physical activity opportunities in the community}

- Use community recreation centre programs, fitness centres, outdoor recreation areas (e.g., parks, skateboard areas)

- Use community mapping exercise (e.g., find out where community physical activities are, what is offered, cost)

- Include familiarity tours of community facilities (rinks, pools). Students want to feel comfortable that they know what they are doing 


\section{Summary}

I have provided a range of suggestions into where and how to target pedagogical practices in physical education to better achieve the learning outcomes for female students, a group who's needs have been underserved. These practices are grounded in female students' need for relatedness, a concept associated with self-determination theory of motivation. The concept of relatedness with its relationship to motivation and subsequent impact on aspects of participation is valuable in helping to better understand the general PE learning environment. Given this theoretical backdrop and growing evidence base, there would appear to be a sound rationale for teachers to implement relatedness-supportive teaching strategies. Continuing to develop a comprehensive understanding of and response to adolescent girls' needs allows us to create the best possible learning environment through which physical education learning outcomes can be achieved.

\section{References}

Azzarito, L, Solmon, M.A., \& Harrison, L.J. (2006). "...If I had a choice, I would..." a feminist poststructural perspective on girls in physical education. Research Quarterly for Exercise and Sport, 77(2), 222-239.

Bryan, C. L., \& Solmon, M. A. (2007). Selfdetermination in physical education: designing class environments to promote active lifestyles. Journal of Teaching in Physical Education, 26(3), 260-278.

Camacho-Minano, M.J., LaVoi, N.M., \& BarrAnderson, D.J. (2011). Interventions to promote physical activity among young and adolescent girls: a systematic review. Health Education Research, 26(2), 1025-1049.

Cox, A.E., Duncheon, N., \& McDavid, L. (2009). Peers and teachers as sources of relatedness perception, motivation, and affective responses in physical education. Research Quarterly for Exercise \& Sport, 80(4), 765-773.

Cox, A.E., \& Williams, L. (2008). The roles of perceived teacher support, motivational climate, and psychological need satisfaction in students' physical education motivation. Journal of Sport \& Exercise Psychology, 30, 222-239.
Deci, E.L., \& Ryan, R.M. (1985). Intrinsic motivation and self-determination in human behavior. New York: Plenum.

Deci, E.L., \& Ryan, R.M. (2000). The "what" and "why" of goal pursuits: Human needs and the self-determination of behavior. Psychological Inquiry, 11, 227-268.

Dowler, W. (2012). Cooperative learning and interactions in inclusive secondary-school physical education in Australia. In B. Dyson \& A. Casey (Eds.). Cooperative learning in physical education: A research-based approach (pp. 150-165). New York: Routledge.

Dyson, B. \& Casey, A. (2012). Cooperative learning as a pedagogical model in physical education. In B. Dyson \& A. Casey (Eds.). Cooperative learning in physical education: A research-based approach (pp. 1-12). New York: Routledge.

Ebbeck, V., \& Gibbons, S.L. (1998). The effect of a team building program on the selfconceptions of grade 6 and 7 physical education students. Journal of Sport and Exercise Psychology, 20, 300-310. 
Eime, R., Harvey J.T., Sawyer, N.A., Craike, M.J., Symons, M., Polman, R., et al. (2013). Understanding the contexts of female participation in sport and physical activity. Research Quarterly for Exercise and Sport, 84(2), 157-166.

Felton, G., Saunders, R., Ward, D., Dishman, R., Dowda, M., \& Pate, R. (2005). Promoting physical activity in girls: A case study of one school's success. Journal of School Health, 75(2), 57-62.

Flintoff, A., \& Scraton, S. (2001). Stepping into active leisure? Young women's perceptions of active lifestyles and their experiences of school physical education. Sport, Education and Society, 6(1), 5-21.

Gano-Overway, L.A. (2013). Exploring the connections between caring and social behaviors in physical education. Research Quarterly for Exercise and Sport, 84(1), 104-114.

Gibbons, S.L. (2009). Meaningful participation of girls in senior physical education courses. Canadian Journal of Education, 32(2), 222-244.

Gibbons, S.L., \& Ebbeck, V. (2011). Team building through physical challenges in gendersegregated classes and student self-conceptions. Journal of Experiential Education, 34(1), 71-86.

Gibbons, S.L., Ebbeck, V., Concepcion, R.Y., \& Li, K. (2010). The impact of an experiential education program on the self-perceptions and perceived social regard of physical education students. Journal of Sport \& Exercise Psychology, 32, 786-804.

Gibbons, S.L., \& Gaul, C. A. (2004). Making physical education meaningful for young women: Case study in educational change. Avanté, 10(2), 1-16.

Gibbons, S.L., \& Humbert, M.L. (2008). What are middle school girls looking for in physical education? Canadian Journal of Education, 31(1), 167-186.

Gibbons, S.L., Humbert, M.L., Temple, V.A. (2010). Making physical education meaningful for girls: Translating theory to practice. PHEnex Journal, 2(1), 1-20. Retrieved from: http://ojs. acadiau.ca/index.php/phenex/article/view.
Gibbons, S.L., Wharf Higgins, J., Gaul, C., \& Van Gyn, G.H. (1999). Listening to female students in high school physical education, Avanté, 5(2), 1-20.

Gordon, B. (2010). An examination of the responsibility model in a New Zealand secondary school physical education programme. Journal of Teaching in Physical Education, 29, 21-37.

Grenier, M., \& Yeaton, P. (2012). The cooperative learning model as an inclusive pedagogical practice in physical education. In B. Dyson \& A. Casey (Eds.). Cooperative learning in physical education: A research-based approach (pp. 119-135). New York: Routledge.

Hellison, D., \& Martinek, T. (2006). Social and individual responsibility programmes. In D. Kirk, D. Macdonald, and M. O'Sullivan (Eds.). The handbook of physical education (pp. 610-626). London: Sage.

Hills, L. (2006). Playing the field(s): an exploration of change, conformity and conflict in girls' understandings of gendered physicality in physical education. Gender and Education, 18(5), 539-556.

Hills, L. (2007). Friendship, physicality, and physical education: an exploration of the social and embodied dynamics of girls' physical education experiences. Sport, Education, and Society, 12(3), 335-354.

Hurtes, K.P. (2002). Social dependency: The impact of adolescent female culture. Leisure Sciences, 24, 109-121.

Jamner, M.S., Spruijt-Metz, D., Bassin, S., \& Cooper, D. M. (2004). A controlled evaluation of a school-based intervention to promote physical activity among sedentary adolescent females: Project FAB. Journal of Adolescent Health, 34, 279-289.

Leversen, I., Danielsen, A., Wold, B., \& Samdal, O. (2012). What they want and what they get: Self-reported motives, perceived competence, and relatedness in adolescent leisure activities. Child Development Research, Article ID 684157, doi: 10.1155/2021/684157

Lubans, D.R., Okely, A.D., Morgan, P.J., Cotton, W., Puglisi, L., \& Miller, J. (2012). Description and evaluation of a social cognitive model of physical activity behaviour tailored for adolescent girls. Health Education Research, 27(1), 115-128. 
Niemiec, C., \& Ryan, R. (2009). Autonomy, competence, and relatedness in the classroom: Applying self-determination theory to education practice. Theory and Research in Education, 7(2), 133-144.

Ntoumanis, N. (2001). A self-determination approach to the understanding of motivation in physical education. British Journal of Educational Psychology, 71, 225-242.

Ntoumanis, N. (2005). A prospective study of participation in optional school physical education using a self-determination theory framework. Journal of Educational Psychology, 97, 444-453.

Olafson, L. (2002). "I hate phys. ed.": Adolescent girls talk about physical education. Physical Educator, 59, 67-74.

Pascual, C., Escarti, A., Llopis, R., Gutierrez, M., Marin, D., \& Wright, P. (2011). Implementation fidelity of a program designed to promote personal and social responsibility through physical education. Research Quarterly for Exercise and Sport, 82(3), 499-511.

Pfaeffli, L., \& Gibbons, S.L. (2010). Girls getting active: Exploring a physical education program tailored to young women. PHEnex Journal, 2(3), 1-21.

Ruiz, L.M., Graupera, J.L., Moreno, J.A., \& Rico, I. (2010). Social preferences for learning among adolescents. Journal of Teaching in Physical Education, 29, 3-20.

Rutten, C., Boen, F., \& Seghers, S. (2012). How school social and physical environments relate to autonomous motivation in physical education: The mediating role of need satisfaction. Journal of Teaching in Physical Education, 31, 216-230.

Ryan, R.M., \& Deci, E.L. (2002). An overview of self-determination theory. In E.L. Deci \& R.M. Ryan (Eds.), Handbook of self-determination research (pp. 3-33). Rochester, NY: The University of Rochester Press.

Ryan, R.M., \& Deci, E.L. (2007). Active human nature: Self-determination theory and the promotion and maintenance of sport, exercise, and health. In M.S. Hagger \& N. Chatzisarantis (Eds.), Intrinsic motivation and self-determination in exercise and sport ( $p p$. 1-19). Champaign, IL: Human Kinetics.
Sammet, K. (2010). Relationships matter: Adolescent girls and relational development in adventure education. Journal of Experiential Education, 33(2), 151-165.

Shen, B., McCaughtry, N., Martin, J., Fahlman, M., \& Garn, A. (2012). Urban high-school girls' sense of relatedness and their engagement in physical education. Journal of Teaching in Physical Education, 31, 213-245.

Shen, B., McCaughtry, N., Martin, J., \& Fahlman, M. (2009). Effects of teacher autonomy support and students' autonomous motivation on learning in physical education. Research Quarterly for Exercise and Sport, 80, 44-53.

Shen, B., Weidong, L., Sun, H., \& Rukavina, P.B. (2010). The influence of inadequate teacherto-student social support on amotivation of physical education students. Journal of Teaching in Physical Education, 29, 417-432.

Sproule, J., Martindale, R., Wang, J., Allison, P., Nash, C., \& Gray, S. (2013). Investigating the experience of outdoor and adventurous project work in an educational setting using a self-determination framework. European Physical Education Review, 1-14. doi: 10.117/ 1356336X13495629

Standage, M., Duda, J.L., \& Ntoumanis, N. (2003). A model of contextual motivation in physical education: Using constructs from self-determination and achievement goal theories to predict physical activity intentions. Journal of Educational Psychology, 95, 97-110.

Standage, M., Duda, J. L, \& Ntoumanis, N. (2005). A test of self-determination theory in school physical education. British Journal of Educational Psychology, 75(3), 411-433. doi:10.1348/000709904X22359

Standage, M., Duda, J.L., \& Ntoumanis, N. (2006). Students' motivational processes and their relationship to teacher ratings in school physical education: A self-determination theory approach. Research Quarterly for Exercise and Sport, 77, 100-110.

Sun, H. \& Chen, A. (2010). A pedagogical understanding of the self-determination theory in physical education. Quest, 62(4), 364-384.

Ullrich-French, S., McDonough, M., \& Smith, A. (2012). Social connection and psychological outcomes in a physical activity-based youth development setting. Research Quarterly for Exercise and Sport, 83(3), 431-441. 
Van Daalen, C. (2005). Girls' experiences in physical education: Competition, evaluation, and degradation. Journal of School Nursing, 21(2), 115-121.

van den Berghe, L., Vansteenkiste, M., Cardon, G., Kirk, D., \& Haerens, L. (2012). Research on selfdetermination in physical education: Key findings and proposals for future research. Physical Education \& Sport Pedagogy, doi: 10.1080/17408989.2021.732563
Webber, L., Catellier, J., Lytle, L, Murray, D., Pratt, C., Young, D., et al. (2008). Promoting physical activity in middle school girls: trial of activity for adolescent girls. American Journal of Preventive Medicine, 34(3), 173-184.

Weiss, M.R., \& Stuntz, C.P. (2004). A little friendly competition: Peer relationships and psychological development in youth sport and physical activity contexts. In M.R. Weiss (Ed.), Developmental sport and exercise psychology: A lifespan perspective (pp. 165-196). Morgantown, WV: Fitness Information Technology.

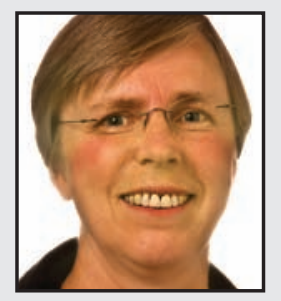

Sandra Gibbons is a Professor in the School of Exercise Science, Physical and Health Education at the University of Victoria in Victoria, British Columbia. Her primary research interest and scholarly contributions focus on increasing meaningful participation of girls and young women in school physical education programs. Her research helps teachers redesign their PE programs to keep more girls actively engaged. A secondary area of research has focused on teaching strategies (primarily team-building, student-centered assessment) to achieve a range of affective learning outcomes. 